\title{
El "plan pistola" como crimen de lesa humanidad en contra de miembros del Ejército Nacional ${ }^{*}$
}

\author{
Recibido: 09 de enero de 2017 - Aprobado: 05 de octubre de 2018 \\ https://doi.org/10.22395/ojum.v18n36a6
}

Jean Carlo Mejía Azuero*

\begin{abstract}
RESUMEN
En Colombia, durante el conflicto armado más prolongado del hemisferio occidental (en adelante, cani), fueron ejecutados a través de prácticas sicariales (ajusticiamientos en términos insurgentes) miembros del Ejército Nacional por parte de grupos ilegales, aprovechando circunstancias especiales como la indefensión, la sorpresa, los permisos, descansos o traslados de una parte a otra del país. El comportamiento criminal descrito, que ha sido definido como "plan pistola", se podría constituir — de acuerdo con el escaso precedente internacional y los desarrollos internos - en crímenes de lesa humanidad (Cassese $\mathcal{E}$ Delmas, 2004) en la modalidad de homicidio agravado contra la población civil, distanciándose de las descripciones propias del derecho internacional humanitario, lo cual constituye toda una novedad, y con lo que de paso se evitaría la impunidad de un crimen tan grave. Las víctimas indirectas del "plan pistola" en un escenario de justicia transicional tienen el derecho a conocer la verdad plena sobre cómo fueron ejecutados sus seres queridos, así como a escuchar de los victimarios cuáles fueron las políticas y órdenes criminales generadas en sus grupos para que sucedieran estos graves hechos sistemáticos o generalizados.
\end{abstract}

Palabras clave: soldados; víctimas; crímenes de lesa humanidad; conflicto armado; justicia transicional; verdad.

\footnotetext{
Artículo de reflexión sobre crímenes cometidos contra los miembros de las Fuerzas Armadas en Colombia, en un contexto diferente al de combatientes o personas protegidas por el derecho internacional humanitario. El presente artículo es resultado del proyecto titulado Desafíos contemporáneos para la protección de derechos humanos en escenarios de posconflicto desde enfoques interdisciplinarios que forma parte de la línea de investigación fundamentación e implementación de los derechos humanos, del grupo de investigación Persona, Instituciones y Exigencias de Justicia, reconocido con categoría Al por Colciencias, registrado con el código COL 0120899, vinculado al Centro de Investigaciones Socio Jurídicas (Cisjuc), adscrito y financiado por la Facultad de Derecho de la Universidad Católica de Colombia.

* Abogado de la Universidad Militar Nueva Granada, Bogotá, Colombia. Especialista en derecho administrativo. Universidad Militar Nueva Granada. Bogotá, Colombia, doctor en Derecho de la Universidad Externado, Bogotá, posdoctor en Derecho de la Universidad Nacional, Bogotá, Colombia. Docente e investigador de la Universidad Católica de Bogotá, Colombia. Correo electrónico: jcmejia@ucatolica. edu.co Orcid: https://orcid.org/0000-0002-7022-7919.
} 


\section{"The Pistol Plan" As a Crime Against Humanity Against Members of the National Army}

\section{ABSTRACT}

In Colombia, during the most prolonged armed conflict in the Western Hemisphere, members of the Colombian National Army were executed through insulting practices ("executions" in insurgent terms) by groups outside the law, taking advantage of special circumstances such as helplessness, surprise or administrative situations, - - e. g. allowances, breaks or transfers- . That criminal behaviour, which has been defined as a "pistol plan" (Plan Pistola), could constitute, in accordance with the international precedent and internal developments, crimes against humanity in the form of aggravated homicide (murder), by distancing itself from the descriptions of international humanitarian law. Indirect victims of the pistol plan in a transitional justice have the right to know the whole truth about how their relatives were executed, as well as to know from the perpetrators what were the policies and criminal orders in their organized groups for that these serious events happened. Keywords: soldiers; victims; crimes against humanity; armed conflict; transitional justice; truth.

\section{0 "plano pistola" como crime contra a humanidade contra membros do Exército Nacional}

\section{RESUMO}

Na Colômbia, dentro do conflito armado (doravante CANI) mais longo do Hemisfério Ocidental, membros do Exército Nacional foram executados por meio de práticas de sicários (ajustamento, em termos insurgentes) por parte de grupos ilegais que aproveitaram circunstâncias especiais, como a indefensabilidade, a surpresa, as permissões, folgas ou traslados de uma parte a outra do país. O comportamento criminoso descrito foi definido como "plano pistola" e poderia constituir — de acordo com o escasso precedente internacional e os desenvolvimentos internos - crimes contra a humanidade (Cassese E Delmas, 2004) na modalidade de homicídio agravado contra a população civil, o que se distancia das descrições próprias do direito internacional humanitário, que constitui uma novidade e, ainda, evita a impunidade de um crime tão grave. As vítimas indiretas do "plano pistola" em um cenário de justiça transicional têm o direito de conhecer a verdade plena sobre como foram executados seus seres queridos, bem como de escutar dos vitimários quais foram as políticas e as ordens criminosas geradas em seus grupos para que sucedessem esses graves feitos sistemáticos ou generalizados.

Palauras-chave: soldados; vítimas; crimes contra a humanidade; conflito armado; justiça transicional; verdade. 


\section{INTRODUCCIÓN}

En Colombia se ha librado desde hace más de tres lustros una disputa a nivel jurídico-político por el reconocimiento de muchos sectores de víctimas generadas en un contexto de guerra, entre ellos el militar y el policial. La controversia, desde que comenzaron los diálogos oficiales en la Habanal y recientemente en Quito con el Ejército de Liberación Nacional (ELN), se ha extendido mucho más allá del ámbito judicial y académico y se ha trasplantado a escenarios de justicia transicional (Teitel, 2000) liderados en buena medida por algunos sectores académicos, estados y organismos nacionales e internacionales que proponen la misma narrativa desde décadas atrás, enfocada esencialmente en la responsabilidad estatal (Dungel, 2009).

Académicamente, durante los últimos doce años, hemos venido construyendo una línea investigativa a través de diferentes proyectos con enfoque sociojurídico en torno a la sensibilización, el reconocimiento y la caracterización de los fenómenos de victimización contra miembros de las Fuerzas Armadas (FFAA), sustentada en interpretaciones polemológicas (Bouthol, 1970) y en el ius in bello (Pictet, 1982) como forma de aproximación contextualizada para la superación de una guerra, eufemísticamente denominada conflicto armado sin carácter internacional de baja intensidad (Kaldor, 2001).

En esta oportunidad se presentan algunos resultados relacionados con el tema de las graves violaciones a los derechos humanos (DDHH) contra los miembros del Ejército Nacional, esencialmente sobre el tópico de la posible configuración de crímenes de lesa humanidad a través de la práctica criminal sistemática y generalizada denominada "plan pistola" desplegada por los grupos armados ilegales en contra de miembros de dicha institución, considerados a la luz del precedente internacional como población civil.

La metodología utilizada se fundamenta en un acercamiento sociojurídico, descriptivo y analítico al tema, se utiliza, además, el método histórico para fundamentar líneas argumentativas sobre precedentes específicos de procesos de victimización por violaciones graves a los derechos humanos (Fisas, 2010) de miembros de cuerpos militares. El trabajo investigativo desarrollado desde el mes de abril del año 2017 se sustentó en fuentes primarias tales como documentos originales de las Fuerzas Armadas Revolucionarias de Colombia-Ejército Popular (FARC-EP), así como en el testimonio de un grupo significativo de desmovilizados. Igualmente existe un número plausible de fuentes secundarias, sobre todo internacionales, que facilitan la comprensión de la problemática planteada alrededor de si es posible jurídicamente considerar a

Con el grupo otrora al margen de la ley FARC-EP. 
militares como víctimas de crímenes de lesa humanidad de origen consuetudinario en el derecho internacional (Meron, 1989) y si es aceptable incluirlos dentro de la definición de población civil, utilizada en la actualidad para describir este tipo de conductas (Greenwood, 1991).

El presente artículo se divide básicamente en tres partes, a saber: en la primera se describen, de acuerdo con los objetivos de la investigación, los principales componentes conceptuales de los crímenes de lesa humanidad a nivel nacional desde la inclusión de militares como víctimas de este tipo de conductas en la experiencia comparada (Cassese, 2008). Una segunda parte en donde se aterriza el tema al caso de víctimas militares colombianas con una descripción analítica sobre la posible existencia de esta conducta delictiva y su importancia en un escenario de justicia de transición. En la parte final se estructuran algunas conclusiones de acuerdo con los hallazgos sobre el "plan pistola" como crimen de sistema.

El objetivo principal de la investigación es sensibilizar al lector a través de una descripción analítica acerca de la existencia de un hecho victimizante de una magnitud inusitada, oculto en términos de macrocriminalidad (Ambos, Malarino y Elsner, 2009). También el presente producto académico tiene los objetivos específicos de definir, caracterizar y mostrar qué es el "plan pistola" como una forma de aportarle a los componentes de verdad judicial y extrajudicial del sistema de justicia transicional colombiano que ya se encuentra retardado para entrar a funcionar plenamente. Si se cumplen los objetivos anteriores, se estará dignificando, de contera, a miles de víctimas de homicidios selectivos, constituyéndose quizás en una forma de reparación simbólica al tratar de mitigar, así sea de forma mínima, un dolor que no debe generarse jamás. Si se quiere superar la guerra para siempre se le tiene que comprender en su real magnitud, entendiendo sus causas reales, sus manifestaciones y sus consecuencias.

\section{BREVE DESCRIPCIÓN CONCEPTUAL SOBRE LOS CRIMMENES DE LESA HUMANIDAD EN COLOMBIA}

Colombia no tiene en la actualidad tipificados delitos de lesa humanidad, lo que de suyo y en el contexto de la finalización del CANI con las FARC-EP podría generar, teniendo en cuenta los estándares internacionales de lucha contra la impunidad (Joinet, 1985), la necesidad de generar una garantía de no repetición a través de una futura descripción sancionatoria en el escenario interno.

La anterior postura conceptual riñe, en alguna medida, con la de la Fiscalía General de la Nación (en adelante FGN) que -pretendiendo interpretar de buena fe la forma de lograr el cumplimiento internacional de las obligaciones estatales en relación con el deber de investigar, juzgar y sancionar la comisión de crímenes de sistema-, ha decidido trasplantar in extenso algunas posiciones altamente debatibles en el mismo 
derecho internacional (Barbosa y Bernal, 2015) y expedir una serie de directivas², por medio de las cuales establece que en la investigación de crímenes de lesa humanidad ${ }^{3}$ deberá tenerse en cuenta la época de comisión de los hechos bajo la integración de los postulados de tipificación de delitos comunes a los cuales se les añaden, según el ente acusador y la Corte Suprema de Justicia (CSI), elementos de contexto del crimen en el derecho internacional (CSJ, 2009, p. 213), es decir la sistematicidad o generalidad de la conducta, con la flexibilización de algunos de los principios apicales del derecho penal. (Fiscalía, 2016a; Fiscalía, 2016b; Fiscalía, 2016c).

Esta posición también contrasta con la esgrimida por buena parte de la doctrina internacional alrededor del nuevo derecho penal internacional (DPI), en donde se indica que el deber de los estados es el de investigar, juzgar y sancionar efectivamente graves conductas que en el escenario internacional pudieran ser consideradas como crímenes de lesa humanidad (Futamura, 2006) así en las disposiciones internas no se les dé tal alcance o denominación (Nomen iuris criminis). Y es que, en realidad, vale la pena indicar que el concepto crímenes de lesa humanidad (anteriormente contra la humanidad o against humanity), no cuenta aún en la actualidad con un consenso a nivel internacional respecto a su origen, conceptualización y al alcance de su persecución, amén de su configuración desde el derecho consuetudinario, pasando por escenarios de tipificación desde Núremberg. Para Antonio Cassese y el profesor Bassiouni, pilares del nuevo DPI, existen históricamente más de doce definiciones sobre este tipo de conducta (Cassese, 2008; Bassiouni, 1992).

Por otro lado, deberá indicarse también que la tipificación que se encuentra en el Estatuto de Roma (ER o el Estatuto en lo sucesivo) del 17 de julio de 1998, solo opera de forma complementaria en el caso colombiano y ello en virtud de lo establecido por la misma jurisprudencia de la Corte Constitucional en sentencias como la C-578 del año 2002 (Corte Constitucional, 2002a) y en la C-290 del año 2012 que precisa que parte del Estatuto integra en sentido restringido el bloque de constitucionalidad, de lo cual se generan consecuencias judiciales específicas para caso concreto.

Puntualmente, frente a los crímenes de lesa humanidad, la Corte Constitucional ha concluido que el artículo $7^{\circ}$ del ER sí hace parte del bloque, lo cual obliga a todos los operadores judiciales en Colombia, y a los demás servidores públicos, a interpretar la normatividad interna desde los parámetros establecidos en el ER para la comisión de este tipo de conductas (Corte Constitucional, 2002b), a partir del primero de noviembre del año 2002, exceptuando los casos de conductas de trato sucesivo. En ese sentido, entre las interpretaciones que han variado con la evolución del Derecho Internacional

2 Actos administrativos.

3 Admitiendo su existencia en el país desde 1976 sin claridad conceptual a nivel internacional a partir de 1976 fecha de entrada en vigencia del Pacto Internacional de Derechos Civiles y Políticos. 
de los Derechos Humanos (DIDH) se encuentra la de comprender que los crímenes de lesa humanidad han dejado en el DPI de ser cometidos solo por agentes del Estado desde el escenario post-Núremberg superando también expresiones como la de dicho Estatuto en el artículo 6 (c) (Tribunal Militar Internacional. IMT, 1945) o la Ley 10 del Consejo de Control de Alemania (en adelante CCA) que ligaba la comisión de los crímenes de lesa humanidad a escenarios prebélicos o bélicos (Corte Constitucional, 2002 b; Corte Constitucional, 2006a).

Lo que sí resulta claro en la actualidad es que los crímenes de lesa humanidad se cometen contra la población civil, en cualquier tipo de escenario (prebélico, bélico, en posacuerdo, posconflicto (Sierra-Zamora, 2018) o períodos de paz) y deben constituir un ataque sistemático o generalizado ${ }^{4}$ (macrocriminalidad) que afecte notoriamente a la humanidad como un todo, pues el interés de protección de la dignidad humana es universal, por ello no pueden quedar en impunidad y es deber primordial de los Estados perseguirlos, juzgarlos y sancionarlos debidamente, tal y como lo han señalado, entre otras, la Corte Interamericana de Derechos Humanos (Corte IDH en adelante) y la Corte Europea de Derechos Humanos (Corte EDH en adelante) y los tribunales penales internacionales ad hoc, mixtos y la misma Corte Penal Internacional (CPI en adelante) (Corte IDH, 2006; Corte IDH, 2010; Corte EDH, 2001a; Corte EDH, 2008; Corte EDH, 2001b; Corte Penal Internacional. CPI, 2014). El problema principal para el caso colombiano consistirá en verificar sí los miembros del Ejército Nacional en determinadas circunstancias caben dentro de la categoría población civil, como ha sucedido en la experiencia internacional en otras latitudes, pero no en América Latina (Ambos, Malarino y Elsner, 2009).

\subsection{Contexto de la comisión de los crímenes de lesa humanidad en Colombia}

Teniendo siempre presente el deber del Estado colombiano de investigar, juzgar y sancionar debidamente los crímenes nucleares, de sistema o la macrocriminalidad en términos políticos (Ambos, Malarino y Elsner, 2009), habrá que indicar que, no obstante no encontrarse tipificación alguna de los crímenes de lesa humanidad a nivel interno, sí se encuentran establecidos delitos, que debidamente contextualizados permiten que Colombia cumpla con sus obligaciones internacionales, mucho más en un escenario transicional de terminación del CANI con las FARC-EP; quedando en armas, de acuerdo con el artículo $1^{\circ}$ del Protocolo Adicional II de Ginebra de 1977 (Comité Internacional de la Cruz Roja. CICR, 1977), el Ejército de Liberación Nacional (ELN en adelante)5 , y

4 En términos del artículo 7 del ER tenido en cuenta por el AL 01 del 2017 se emplean las condiciones de contexto "sistemático" o "generalizado", así que para la obtención de la verdad judicial y extrajudicial se tendrá que probar a través de los medios aceptados que existió un plan, una política, una estrategia, ordenes de cometer crímenes de lesa humanidad.

5 Al momento de escribirse el artículo el ELN y el gobierno se encuentran en un cese bilateral de hostilidades. 
los denominados por el gobierno del expresidente Santos y luego por la Ley 1908 del 2018 como grupos armados organizados (GAO en adelante) dentro de los cuales se encuentran el "Cartel del Golfo", los "Puntilleros" y los "Pelusos".

Habrá que indicar desde el contexto sociojurídico en primera medida que los crímenes de lesa humanidad en Colombia básicamente se han cometido, en medio del CANI más antiguo del hemisferio occidental ${ }_{\perp}$ en términos polemológicos (estudio científico sobre la guerra) o irenológicos (estudio científico sobre la paz) desde una perspectiva teórica (Galtung, 1998; 2006). De esa forma existirán crímenes de lesa humanidad conexos con el CANI, como las masacres, el desplazamiento forzado, las torturas contra la población civil (con ocasión y en razón de la guerra); pero también existirán crímenes de lesa humanidad cometidos durante el CANI (1964-2017), inclusive, que no han tenido relación directa con la conducción de hostilidades, como los magnicidios contra Luis Carlos Galán, Álvaro Gómez Hurtado, incluso masacres, homicidios, agresiones sexuales, feminicidios entre otros delitos causados por la criminalidad organizada nacional y transnacional. Aquí lo esencial es que esos crímenes hayan sido sistemáticos o generalizados, de una gravedad inusitada (lesa) y con el conocimiento por parte de los autores de que dichas conductas hacían parte de un plan o una política grupal (elemento subjetivo de estos crímenes que no se explicará en este texto por estar fuera del objetivo principal).

De acuerdo con lo anterior, resulta pertinente para el caso colombiano y el presente artículo mirar desde la perspectiva de lucha contra la impunidad, algunos conceptos que pudieran ayudar a investigar, juzgar y sancionar crímenes de lesa humanidad en el contexto de un CANI dentro de un sistema de justicia transicional del cual se espera eficacia, eficiencia y celeridad, garantizando en la práctica el estándar de tribunal independiente e imparcial, fundante del nuevo DPI (Mejía y Sandoval, 2013)

\subsection{El concepto de lesa humanidad}

Para la configuración de estos crímenes (asunto nada sencillo) se ha venido formando lentamente un consenso a nivel internacional luego de la terminación de la Segunda Guerra Mundial en el que el término "lesa humanidad" simboliza la afectación grave a todos los seres humanos a nivel universal, más allá del espacio físico y temporal de la comisión de la conducta. Esa búsqueda de consenso se encuentra plasmada, por ejemplo, en el preámbulo del ER (Corte Constitucional, 2002a).

Los crímenes de lesa humanidad son una afrenta contra todas las personas naturales sin importar su origen, raza, sexo, costumbres, creencias, nacionalidad o demás particularidades, por eso es un deber de los estados perseguirlos, investigarlos, juzgarlos y sancionarlos en cualquier momento en virtud de su imprescriptibilidad, de lo 
contrario la comunidad internacional a través del DPI centralizado o descentralizado (tribunales ad hoc, mixtos, tribunales nacionales que persigan crímenes internacionales como Alemania y su código del año 2002) amén de la jurisdicción universal y la cooperación judicial, se encargará de que no exista impunidad.

Desde esa perspectiva, humanidad hará alusión a todos los individuos de la especie humana, sin importar su oficio u profesión. Este es un término incluyente, amplio y conglobante pues hunde sus orígenes en el mismo DIDH, especialmente en la Declaración Universal de Derechos Humanos (DUDH en adelante) y en el Pacto Internacional de Derechos Civiles y Políticos de 1966, que entró en vigencia en el año de 1976 (PIDCP en adelante).

Por otro lado el término lesa, que reemplazó al de contra (en castellano, en inglés sigue siendo crimes against humanity), y que se utilizó en la Carta de Londres de 1945, muestra la magnitud del ataque o la agresión contra la humanidad en cualquier escenario espacial y temporal, mucho más allá de la afectación propia de un delito común o incluso del proveniente de la delincuencia organizada. No se tratan estos crímenes de conductas entonces aisladas, incluso esporádicas, sino de planes criminales complejos, expuestos en políticas públicas (Sierra-Zamora, et al, 2015) y estrategias y manifestados en órdenes de cualquier naturaleza, bien sean escritas o verbales.

\subsection{Concepto de población civil}

Así como existe una evolución en el concepto de lesa humanidad para la configuración de crímenes que permiten evidenciar toda una política o un plan para atacar de forma sistemática o generalizada a la población civil, también se habrá de indicar que este término también cuenta en la actualidad con una aproximación conceptual amplia en muchas instancias académicas (Bassiouni, 1992; Cassese, 2008; Joyner y Bassiouni, 1998) y judiciales (Tribunal Penal Internacional para la Antigua Yugoslavia. TPIY, 2008), haciendo alusión en tiempos de paz a todos los integrantes de una sociedad, comunidad e incluso de una nación, sin criterios de exclusión en virtud de la naturaleza de los ataques.

Es pertinente precisar que cuando se alude a este tipo de conductas desplegadas en tiempos de guerra se puede en ocasiones entender el término población civil desde consideraciones diferentes a las que se plantean en escenarios propios al del combate en donde cualquier vulneración a la dignidad humana podría mirarse más cercana a una infracción al Derecho Internacional Humanitario (DIH en adelante) y bajo las convergencias entre este cuerpo jurídico y el DIDH (Nicholson, 2016). En consecuencia, se podrían entender incluso en CANI que los conceptos lesa humanidad y población civil parten de visiones amplias e incluyentes y no de posiciones cerradas 
en virtud de la naturaleza de este tipo de contiendas bélicas y su especial ámbito de protección. De esa forma se puede ir abriendo una interpretación esencial dentro del contexto colombiano.

\subsection{El militar como parte de la población civil. Experiencia comparada}

Existe un problema central en la configuración de crímenes de lesa humanidad dentro de contextos altamente ideologizados como el de los CANI en donde la guerra magnifica su expresión política en términos de Clausewitz (2005); ¿Podrán ser los militares víctimas de crímenes de esta naturaleza o, por el contrario, estos crímenes solo pueden cometerse contra personas que no integran los actores armados?

Para tratar de resolver el problema teórico-práctico planteado desde el inicio habría que mirar qué ha pasado en la experiencia comparada teniendo en cuenta las fuentes del Derecho Internacional Público a saber; el derecho consuetudinario, el derecho de los tratados, la jurisprudencia y la doctrina ${ }^{6}$.

Desde el punto de vista del derecho consuetudinario (la costumbre), no se encuentra ningún tipo de regla o norma que excluya al ser humano militar de su condición de integrante de la población civil, más aún cuando se encuentra en circunstancias temporales desligadas a su quehacer profesional, incluso en situaciones que comporten la existencia de una guerra, eufemísticamente hoy denominada conflicto armado (Mejía, 2016). Es más, la construcción de la Declaración de San Petersburgo (1868) y la Cláusula Martens (1899) precedentes en el siglo XIX de la denominación de crímenes contra la humanidad fueron pensadas primordialmente en un contexto en donde las víctimas principales de las guerras eran los militares, así como los integrantes de los cuerpos sanitarios (Moir, 2006).

A nivel convencional, ni en el DIDH actual, ni en el DIH existe una norma que establezca la exclusión de los soldados como parte de la población civil, mucho menos bajo la evolución que ha tenido el concepto desde la finalización de la II Guerra Mundial y las vertientes configurativas post-Núremberg, empezando por el artículo 6 c) del Estatuto, incluyente a todas luces, así como la Ley 10 de 1945 del Consejo de Control Alemán en su artículo II (CCA, 1945), inclusivo también y extendido a escenarios diferentes al bélico. Aquí se evidencia en un contexto de guerra actual la importancia de las convergencias entre normas humanitarias y normas de protección al ser humano provenientes de la DUDH y el PIDCP que tiene su mayor expresión actual en el ER, para el caso específico en el artículo $7^{\circ}$ en donde se establecen los crímenes de lesa

6 El abordaje también es práctico en virtud de la obligación de Colombia en la actualidad de implementar adecuadamente el Sistema Integral de Justicia, Verdad, Reparación y No Repetición fruto de sendos actos legislativos y decretos ley de los años 2016 y 2017. 
humanidad sin salvedad ninguna hacia quienes hacen parte de las FFAA, bajo una definición amplia de población civil (Schabas, 2012).

Ahora bien, la jurisprudencia del Tribunal Penal Internacional para la Antigua Yugoslavia (TPIY) abrió líneas de interpretación más actualizadas en relación a términos como población civil, incluyendo en varias sentencias la posibilidad de que miembros de los cuerpos de seguridad (Sierra-Zamora, et al, 2019, pp.309-325) ora militares ora policiales, milicias y combatientes en general, en determinadas circunstancias pudieran ser víctimas de crímenes de lesa humanidad, sobre todo cuando no pueden estar protegidos de la definición hors de combat ${ }^{7}$ o fuera de combate ligada al DIH. Allí han surgido toda serie de controversias respecto a si los militares, milicias y cuerpos de resistencia pueden ser víctimas de crímenes de lesa humanidad en situación hors de combat, teniendo en cuenta el alcance conceptual del crimen de acuerdo con el estatuto del tribunal, artículo $5^{\circ}$. En los casos de justicia para la transición en América Latina estos debates lastimosamente no se han dado, tal y como lo demuestran varias fuentes (Ambos, Malarino y Elsner, 2009; Fiscalía, 2016c).

Casos en el Tribunal para la Antigua Yugoslavia como Tadic (TPIY, 1995) en la providencia sobre reconocimiento de jurisdicción (párr. 141) y precedentes como Martic (TPIY, 2008), Kupreskic (TPIY, 2000a), Blaskic (TPIY, 2000b), Kordic y Cerquez (TPIY, 2001), Mrskic y otros (TPIY, 2007), Jelisic (TPIY, 1999) y Delalic (TPIY, 1998) son obligatorios, en consecuencia, en virtud de las diferentes aproximaciones al término población civil en relación con militares así como los virajes jurisprudenciales de los casos Martic, y Mrskic (2008). Los anteriores precedentes brindan una línea argumentativa plausible para el caso interno.

De igual manera, en la situación de Ruanda, el tribunal creado para investigar, juzgar y sancionar los graves crímenes cometidos en ese territorio en 1994 asumió el tema generando una jurisprudencia que la JEP podría estudiar en el caso colombiano para que no se genere impunidad frente a miles de militares víctimas asumiendo una interpretación amplia (Huertas y Cáceres, 2017).

Entre los más importantes precedentes sobre el tema de soldados víctimas de crímenes de lesa humanidad se encuentran el del Alcalde Akayesu (TPIR, 1998), el de Kayishema (TPIR, 1999); el terrible asesinato de 10 miembros del ejército belga integrantes de los cuerpos de paz que fueron ultimados luego de ser detenidos por parte del ejército ruandés, caso en el cual el mandato de la misión de paz no incluía

7 Sobre este tópico en especial hay mucha controversia sobre todo a nivel jurisprudencial, pero es tan solo una de las variables a través de las cuales se puede configurar un crimen de lesa humanidad en contra de soldados.

8 Sentencia hito en donde se explica qué se entiende por población civil. 
combatir por lo que fueron considerados como población civil. El criterio utilizado no fue el de su profesión sino el de su vulnerabilidad, Théoneste Bagosora y otros (TPIR, 2008; TPIR, 2014).

Lo mismo ha pasado posteriormente en tribunales mixtos como el de Camboya (ECCC en adelante) con el juzgamiento de los terribles crímenes cometidos por los Khmer Rouge entre abril de 1975 y enero de 1979 (Deutsch y Coleman, 2000); las salas especiales creadas pueden llegar a tener la jurisprudencia más evolucionada y contextualizada sobre el tema como el denominado caso 001 (Tribunal para el Genocidio Camboyano. ECCC, 2010); el cas0 002 (ECCC, 2014); complementado el precedente con las providencias de tribunales internos como los franceses (en diferentes instancias) en donde se juzgó entre otros a Klaus Barbie por crímenes cometidos contra miembros de la resistencia francesa en la II Guerra Mundial. La premisa aquí es que no toda afectación a la dignidad humana de un soldado ciudadano en medio de una guerra puede enmarcarse como crimen de guerra y tampoco puede quedar en impunidad, como en algún momento histórico se pensó por parte, incluso, de la Comisión de Derecho Internacional de la ONU (Killean, Dowds y Kremer, 2017).

Finalmente la FGN en las directivas citadas (2016b) sobre cómo deben investigarse los crímenes de lesa humanidad en Colombia, a fin de cumplir con los deberes del Estado Colombiano, trajo a colación lo expresado a nivel doctrinal por varios autores, en donde en abstracto no se niega la posibilidad de que miembros de las Fuerzas Militares puedan ser tenidos como eventuales víctimas de crímenes de lesa humanidad, más allá de las previsiones alrededor de que se entiende por persona protegida en el DIH, específicamente en el artículo $3^{\circ}$ común de donde se deriva la definición de persona protegida por encontrarse hors de combat (Mejía y Chaib, 2012).

\subsection{Ataque sistemático o generalizado. Elementos de contexto}

Además de lo establecido hasta aquí como elementos de caracterización de los crímenes de lesa humanidad (a todas luces problémico en muchas de sus aproximaciones dependiendo de su regulación en estatutos y de su evolución histórica y el derecho consuetudinario), lo que realmente puede dimensionar dichas conductas es su carácter de ataque sistemático o generalizado contra la población civil, dependiendo esta circunstancia de cómo hayan sido tipificados bajo la premisa de nullum crimen sine legem praevia.

Desde esta perspectiva se encontraran en el DIDH y en el DPI centralizado y descentralizado descripciones en donde el ataque contra la población civil debe ser sistemático, aludiendo dicho elemento de contexto a la existencia de un plan o una 
política de un grupo en relación con la comisión de atrocidades colectivas que, incluso en la literatura, han resultado difíciles de describir por su magnitud, preparación, patrones, modus operandi y prácticas, verbigracia, cierto tipo de torturas y violencia sexual como ocurrió en Pitesti Rumania (Decu, 2013), Celebici (TPIY) o en las dictaduras del Cono Sur o España (Teitel, 2000), pero también se puede configurar un crimen de lesa humanidad cuando el ataque a la población civil sea generalizado, es decir, cuando la manifestación del plan o política criminal de un grupo organizado o del Estado pueda verificarse probatoriamente como una conducta tendiente a generar efectos plurales, masivos o extendidos en un espacio geográfico y temporal determinado (Forero, 2017).

Ahora bien, la configuración de los crímenes de lesa humanidad desde la perspectiva del ER en su artículo $7^{\circ}$ no exige que el ataque contra la población civil deba ser generalizado y sistemático, por el contrario se utiliza en el Estatuto la letra "o" en vez de la "y", lo que facilitaría de acuerdo con la experiencia la estructuración probatoria del crimen. De igual manera la descripción típica de estas terribles conductas no exige la conexidad respecto a su comisión con la existencia de un conflicto armado (Cubides-Cárdenas E Sierra-Zamora, 2018) como ocurrió después de Núremberg, incluso en estatutos de tribunales ad hoc, salvo en la Antigua Yugoslavia. En la siguiente parte se concretarán los conceptos descritos al caso colombiano desde la perspectiva de una práctica terrible pero desconocida por el país, el denominado "plan pistola".

\section{EL MILITAR COLOMBIANO COMO VÍCTIMA DE CRIMENES DE LESA HUMANIDAD}

En pleno proceso de implementación del Acuerdo del Teatro Colón (y el de la Habana) que permitió la desmovilización y dejación (entrega) de armas de más de siete mil miembros de la guerrilla más antigua del hemisferio occidental, las FARC-EP, se ha diseñado un Sistema Integral de Verdad, Justicia, Reparación y no Repetición (SIVJRNR en adelante) en el que uno de sus componentes es la Jurisdicción Especial para la Paz (JEP en adelante), que deberá satisfacer los derechos de las víctimas del CANI colombiano, bajo las precisas especificidades del contexto propio (García, 2015).

Ha quedado claro en el Acuerdo Final, pero más importante, en las normas que han incorporado el consenso político al ordenamiento interno con las previsiones del tribunal constitucional, que para que una persona natural que ha cometido crímenes pueda hacerse beneficiaria del Sistema deberá contribuir eficazmente al esclarecimiento de lo que sucedió en la guerra y a aportar verdad plena que permita aclarar las conductas por ella cometidas, lo anterior desde una perspectiva de justicia restaurativa, más interesada en lograr una eventual paz estable y duradera que en cumplir con las expectativas retributivas del derecho penal ordinario y clásico, eso sí cumpliendo -hasta ahora en abstracto- con las expectativas de las víctimas directas e indirectas (Corte Constitucional, 2017a) 
En ese escenario, encontramos al mes de diciembre del 2017 de acuerdo con cifras del Ministerio de Defensa Nacional (MDN en adelante) 219.785 víctimas militares y policiales (de acuerdo con la Ley 1448 y otras normas ad hoc que reconocen a los miembros de la Fuerza Pública como víctimas); para el caso específico del Ejército Nacional caracterizadas por 17 hechos victimizantes, sin contar las víctimas indirectas de las conductas desplegadas por los grupos al margen de la ley (MDN, 2017)

Dentro de los hechos victimizantes registrados por las cifras del MDN existen variables que podrían, de acuerdo con el derecho consuetudinario, el DIH, el DIDH, el DPI y el mismo derecho interno, indicar con lo visto ut supra la comisión de crímenes de lesa humanidad en contra de soldados colombianos por hechos relacionado directa o indirectamente con la guerra, tales como el desplazamiento forzado, la violencia sexual, entre otros.

De esa forma también encontramos en el Ejército Nacional registros de tortura, reclutamiento forzoso de niños, niñas y adolescentes, y claro está, homicidios (asesinato o murder) contra soldados de diferente graduación, que bien podrían haberse generado de forma masiva amén un estatus de protección general no proveniente de una acción bélica (de acuerdo con el artículo $3^{\circ}$ común de los cuatro convenios de Ginebra), o en circunstancias específicas de indefensión o vulnerabilidad (descanso, permisos, en actividades no relacionadas con las hostilidades ni que impliquen el uso de armas; en desplazamientos no armados) lo que podría configurar la práctica denominada homicidios selectivos.

\subsection{El soldado ciudadano como una expresión de la población civil en Colombia}

De acuerdo con la jurisprudencia internacional ampliamente esbozada, la literatura existente y la posición la Corte Constitucional y del Consejo de Estado colombiano en relación al concepto de soldado ciudadano, estudiado en otras oportunidades (Mejía, 2017), valdría la pena indagar académicamente sí el militar colombiano cabría en la categoría de población civil, para efectos de ser considerado víctima de crímenes de lesa humanidad, específicamente de homicidios selectivos.

Lo primero que habría que precisar para el caso colombiano es que el término población civil resultaría amplio e incluyente en el desarrollo de la estructuración de la conducta criminal en el derecho consuetudinario y a pesar de que en la hasta ahora exigua jurisprudencia de la CPI sobre el tópico se ha querido limitar la interpretación sobre el concepto, como en el caso Katanga relacionado con la masacre de Bogoró en el Congo en el 2003 (CPI, 2014), no existe, en consecuencia, una posición concluyente, ni mucho menos pacífica trasplantable y se cuenta, al contrario, con el respaldo his- 
tórico, doctrinal y jurisprudencial para defender el criterio amplio de víctima. Esto ha sido acogido por la propia FGN (2016 b, p. 19) y el precedente internacional.

En segundo término es esencial indicar académicamente que bajo la hipótesis de una situación de paz estable y duradera en Colombia, cabría incluso la posibilidad de que también los soldados pudieran ser víctimas de crímenes de lesa humanidad bajo la interpretación del concepto amplio de población civil (aplicación principio pro victimae) si sufren un ataque sistemático o generalizado que sea consecuencia de una política o plan de una organización criminal, incluso dentro de las propias fuerzas (empresas criminales). Ha indicado Cassese, citado por Killeam:

Plainly, in time of peace military personnel to many become the Objects of crimes against humanity at the hands of their own authorities. By the same token, in times of armed hostilities, there is no longer any reason for excluding servicemen, whether or not hors de combat (wounded, sick, or prisoners of war) from protection against crimes against humanity (chiefly persecution) whether committed by their own authorities, by allied forces, or by the enemy (Killeam, Dowds y Kremer, 2017, p. 17) ${ }^{9}$.

En tercer lugar, el marco constitucional, legal y jurisprudencial interno en relación a la condición del ser humano que presta su servicio al pueblo colombiano como soldado ha sido amplia e inclusiva y no le quita, siguiendo los parámetros del nuevo DIDH, ni su condición de persona, ni mucho menos de integrante de la población civil para efectos de la configuración de un crimen de lesa humanidad (Corte Constitucional, 1997; Marín y Mejía, 2015).

Finalmente, el contexto polemológico en Colombia y la caracterización de la guerra como un CANI asimétrico, de cuarta generación, irregular (Lind, Nightengale, Schmitt, Sutton y Wilson, 1989; Kaldor, 2001; Hoffman, 2007), permitiría configurar desde una interpretación cerrada o excluyente contraria a los estándares internacionales todo un marco de impunidad frente a hechos criminales contra miembros de las FFAA que si bien fueron cometidos con ocasión y nexo con el CANI, no pueden configurarse como graves infracciones al DIH, por tanto crímenes de guerra, más aún, como graves crímenes de guerra (sistemáticos) como equivocadamente quedo en el Acuerdo Final del Teatro Colón, en la legislación interna y que increíblemente fue avalado (Corte Constitucional, 2017a) en parte por el tribunal constitucional colombiano (Corte Constitucional, 2017b), no obstante las advertencias de la Fiscal Bensouda de la CPI (CPI, 2017).

9 Claramente, en tiempos de paz el personal militar también puede convertirse en objeto de crímenes de lesa humanidad por parte de las autoridades estatales de su país. Por la misma razón, en tiempos de conflicto armado no existe ninguna razón para excluir a los militares, estén o no fuera de combate (heridos, enfermos, como prisioneros de guerra, retenidos o secuestrado) de su protección contra los crímenes de lesa humanidad (principalmente persecución), ya sean cometidos por sus propias autoridades, por fuerzas aliadas o por el enemigo (traducción libre del autor). 
Como conclusión liminar y apical puede decirse que en Colombia, tanto en el escenario de la justicia para la transición como en el de la justicia ordinaria y en cualquier tiempo, debe utilizarse un concepto amplio e incluyente de población civil como se describió analíticamente en acápites precedentes, incluyendo dentro de ese concepto a los miembros de las FFAA, siempre y cuando que por lex specialis no queden bajo el manto de aplicación del DIH como personas protegidas por acciones directas del enemigo o por las circunstancias previstas en el DIH.

\subsection{El "plan pistola" (homicidios selectivos) como práctica sistemática o generalizada en contra de los soldados colombianos}

Uno de los más graves y antiguos fenómenos criminales del CANI en Colombia, de esa etiología de una violencia muy especial llamada guerra, ha sido el de los homicidios selectivos de miembros de las FFAA. Habrá que decirse que el "plan pistola" como se le denomina mediáticamente ha sido poco estudiado en el país, ocultado quizás por los estudios de la "violentología" amen de la terrible afectación de millones de personas particulares sin relación alguna con los actores armados (Guzmán, Fals y Umaña, 2015a; Guzmán, Fals y Umaña, 2015b).

Los siguientes acápites tratan de describir brevemente el fenómeno criminal entendiendo las dificultades metodológicas y prácticas del ejercicio, habida cuenta de problemas estructurales como la ausencia de literatura, la falta de caracterización puntual del hecho victimizante, la inexistencia de bases de datos unificadas y que correspondan a criterios previamente establecidos, la priorización de otros hechos victimizantes por parte de las autoridades, las presiones de ciertos sectores, entre otros.

El propósito principal inmediato del ejercicio, como se expuso en la introducción es contribuir desde lo académico al esclarecimiento de la verdad (judicial y extrajudicial) dentro de un contexto de superación del CANI con las FARC-EP y aportar una herramienta de sensibilización y conocimiento sobre un hecho victimizante singular para que sea eventualmente utilizado por los mecanismos del SIVIRNR. De forma mediata el objetivo es dignificar a los miles y miles de víctimas militares (incluyendo las familias). Estos objetivos giran en torno al problema central propuesto, la posibilidad o no que los soldados colombianos sean reconocidos como víctimas de crímenes de lesa humanidad.

Para ello se tendrán en cuenta documentos de las FARC-EP cuando eran grupo armado ilegal, obtenidos para efectos académicos desde varias fuentes, compilados y consultados vía web en otras investigaciones previas (Mejía, 2009); de igual forma los relatos de veintiún desmovilizados de grupos armados ilegales y una estadística básica proveniente del sector Defensa. 


\subsubsection{Definición y descripción del "plan pistola"}

Teniendo en cuenta el contexto de CANI y los documentos del otrora grupo al margen de la ley FARC-EP, en los que, desde la misma descripción como estructura, las FARC aceptan su naturaleza armada y el uso de la combinación de medios militares y políticos para la consecución de la toma del poder (Vieira, 1964; Pizarro, 1991), se puede decir que el "plan pistola" es una práctica de homicidio selectivo contra miembros de las FFAA dentro de una estrategia militar que utiliza inteligencia de combate a fin de obtener una ventaja táctica con repercusiones psicológicas y mediáticas respecto a la condición de vulnerabilidad temporal o circunstancial del servidor público frente a quien se ejerce como enemigo natural.

En ese caso, el "plan pistola" se puede describir como una acción criminal premeditada y expresada en políticas y planes de un grupo, que se ejerce contra un adversario militar (que representa además una visión política adversarial en términos polemológicos), aprovechando las labores de inteligencia cuando el soldado se encuentra en una situación específica no relacionada con la conducción de hostilidades, que incluso puede ser originada en situaciones administrativas como un descanso, vacaciones, de permiso o, incluso, en desplazamientos.

El objetivo principal del "plan pistola" es militar, pero también tiene efectos políticos, mediáticos y psicológicos pues busca generar la sensación de control territorial, control sobre la población, destrezas en la inteligencia de combate, miedo y zozobra en los adversarios y cumpliría, además, un rol complementario a nivel operacional al que se pretende con el uso de francotiradores y minas, como lo registran los desmovilizados entrevistados.

También se puede concluir que el "plan pistola" hace parte de una política de homicidios individuales y grupales de las FARC-EP, así, también se pueden hallar asesinatos como forma de control social externo ("los colaboradores del adversario"), control social interno (como mecanismo de control disciplinario), control territorial a partir de la generación de miedo (masacres), control político como la muerte de alcaldes, concejales, congresistas, entre otros (Mejía, 2009).

\subsection{2. "Plan pistola" en los documentos de las FARC-EP}

Existen documentos desde los inicios de las FARC como bloque sur (1964) en donde se hace alusión a los ajusticiamientos (homicidios selectivos), ligados a prácticas, modus operandi y algunos patrones heredados de la violencia política de los años cuarenta y cincuenta y que han sido estudiados por los violentólogos de la Universidad 
Nacional desde la publicación de textos sobre la violencia de Fals Borda, Umaña y Guzmán 2015a; 2015b).

La Séptima Conferencia de las FARC (1982) y sus plenos, como proyección de la visión de las anteriores reuniones, muy especialmente de la sexta de 1978, fortaleció el componente militar dentro de la concepción de combinación de todas las formas de lucha proyectando un ejército del pueblo (Nguyen, 1968) bajo un plan estratégico y la nueva "forma de operar" -un plan militar para contrarrestar al Estado en lo táctico y operacional-y estableció en una de sus conclusiones:

Queda terminantemente prohibido el ajusticiamiento de personas en general sin que antes se haya realizado la investigación correspondiente a cada uno de los casos. No se procederá sobre personas de importancia e influencia sobre las masas sin que antes haya la consulta directa al Secretariado (FARC, 2007, p. 254)

Lo anterior demuestra que ningún homicidio selectivo (ajusticiamiento) se realizaba sin consultar a los mandos superiores del grupo armado. Es más, las FARC contaban con toda una política de ajusticiamientos internos (purgas), y externos respecto a las "masas" y también en relación con la población civil perteneciente funcionalmente al Estado.

En el documento denominado Compendio militar (FARC, 2007), al cual se tuvo acceso en esta investigación y que contiene todos los lineamientos organizacionales y operativos de las FARC, compilados después de la IX Conferencia de la organización se encuentra una manifestación de su otrora máximo dirigente denominada Tesis Manuel $^{10}$, redactada en mayo del 2006 en donde hace alusión al tema de los ajusticiamientos indicando:

Mientras comprobamos la veracidad de los informes las medidas tomadas preventivamente fueron expulsión de la región de los cooperantes, el ajusticiamiento de dos y la permanencia de dos bajo vigilancia y el compromiso de suministrar información oportuna del desplazamiento del ejército en las regiones. Esta es una medida preventiva aplicada aquí para esta región, falta conocer los resultados más tarde (FARC, 2007, p. 173)

Ahora bien, puntualmente en relación con la práctica denominada "plan pistola" como una expresión de ataque selectivo, sistemático o generalizado en contra de los miembros de las FFAA, en especial contra de soldados del Ejército Nacional, para efectos de la presente investigación, se encuentra el texto Orientaciones generales producido por alias Jorge Briceño en el año 2002 en donde sostiene:

10 Proyecto de ponencia de Manuel Marulanda Vélez para la IX Conferencia de las FARC de acuerdo con el Pleno ampliado del año 2000. 
23. A partir del 30 de enero de 2003 cada Frente da de baja diario a un miembro de la fuerza pública en su área, fuera de los hostigamientos, emboscadas, asaltos y combates que están en los planes de cada uno. Todos los mandos deben estar al Frente de estas misiones por que los nuevos no saben y por eso la actividad combativa no funciona como mandan nuestros planes (Estado Mayor del Bloque Oriental. EMBO, 2002, p. 3).

Resulta claro entonces que los ajusticiamientos (homicidio o asesinato) en las FARC contaban con un direccionamiento general de la organización expresado en planes, directrices y órdenes y que el "plan pistola" iba mucho más allá de una concepción bélica que respetase el ius in bello (DIH), pues los modus operandi principales consistían en acciones sorpresivas, emanadas de actividades de inteligencia de combate (de valor estratégico para las FARC, no solo con sentido a nivel operacional o táctico), aprovechando especiales circunstancias de las víctimas como la indefensión y con el uso, incluso, de medios prohibidos en la conducción de hostilidades.

Luego de la eficiencia innegable del poder aéreo por parte del Estado expresado en operaciones conjuntas, coordinadas e interagenciales con componentes militares y policiales (Ugarriza y Pabón, 2017), las órdenes de ajusticiar a militares, especialmente pilotos, se hicieron más notorias, incluso en las ciudades y a través de milicias o comisiones específicas, como fue ordenado en la VIII Conferencia y el Pleno del año 2000. Otro documento al que se tuvo acceso para efectos académicos demuestra una vez más la posición de las FARC respecto al tema.

Al fin y al cabo esos pilotos...todo el tiempo no están en el aire, esos se bajan y también tienen familia y van a la casa y allá los puede uno ubicar y darles pistola ventiada o capturarlos sin contemplaciones, entonces dese cuenta que hay formas de combatirlos también y vamos hacerle (sic) la vida imposible a todos los que nos están creando problemas (Estado Mayor del Bloque Oriental. EMBO, 2000)

En resumen, se puede decir que las FARC-EP, mientras fue una organización ilegal, mantuvo políticas, planes y órdenes precisas en relación con lo que se debía hacer con traidores (población civil), adversarios en circunstancias que no tenían nexo causal directo con la conducción de hostilidades. De igual forma, frente a empresarios, políticos y algunos extranjeros. El "plan pistola" fue una "práctica político-militar ampliamente efectiva" para la insurgencia en muchas de las fases de la guerra en Colombia y los elementos evidenciados pueden ayudar a preservar el derecho a la verdad de miles de víctimas en Colombia, esta vez de las víctimas integrantes del Ejército Nacional.

\subsection{3. "El plan pistola" desde la mirada de los desmovilizados}

Durante el trabajo de campo para la investigación relacionada con el "plan pistola" como una posible práctica constitutiva de crímenes de lesa humanidad en contra de 
los miembros del Ejército Nacional, tuvimos la oportunidad tener acceso a veintiún desmovilizados de diferentes estructuras, incluso de grupos que se mantienen todavía al margen de la ley.

Sus testimonios son prueba casi irrefutable de que el denominado "plan pistola" fue una práctica colectiva, realmente masiva, llevada a cabo a nivel nacional, pues los entrevistados pertenecían a estructuras ubicadas a lo largo y ancho del país. Por otro lado, el plan, de acuerdo con las fuentes primarias, correspondía a diferentes modus operandi, que iban desde seguimientos y vigilancias a las víctimas en lugares apartados al área de influencia del grupo armado, hasta la utilización de "mujeres bellas" para provocar el engaño en los miembros del Ejército Nacional.

En ocasiones, ni siquiera se utilizaban medios como motos o carros para lograr el propósito criminal, ni armas cortas, sino granadas o explosivos y se ejecutaba el acto criminal a pie, tal y como lo describió alias "Dember"11 desmovilizado de la columna móvil Daniel Aldana con injerencia para esta actividad en Tumaco en Nariño (Dember, 2017)

La práctica criminal descrita en palabras de los desmovilizados tenía varios propósitos político-militares y de control social, territorial, demostración de capacidades como la inteligencia de combate, infiltración y penetración. Por ejemplo, alias "El Sangrón" quien fue cabecilla de escuadra del frente 62 de las FARC (combatientes del Yari) sostiene que el "plan pistola" era una fortaleza ya que no afectaba a la población civil sino al militar (Sangrón, 2017).

Además de lo hasta aquí descrito, el "plan pistola", como sucedió desde los años sesenta, tiene un propósito táctico y psicológico en términos polemológicos al generarse algunas veces con el objetivo de hurtar el armamento de la víctima, allí la sorpresa del resultado de los factores preponderantes tal y como lo enseña alias "Zucarina" exintegrante del frente Efraín Pabón de las FARC, segundo cabecilla de comisión y quien explica cómo en Toledo, en Norte de Santander, dos soldados profesionales fueron asesinados y luego les fue hurtado su armamento. (Zucarina, 2017). En el mismo sentido alias el "Crazy" quien describe el mismo modus operandi y patrón en Miraflores, Solita y Florencia, Cauca (Crazy, 2017).

En no pocas ocasiones, el "plan pistola" contra miembros del Ejército Nacional venía acompañado de la presencia de fenómenos de multicriminalidad y delincuencia transnacional, dependiendo de la región. Incluso las armas cortas con las que asesinaban a los miembros de las Fuerzas Militares podían resultar escondidas en otros

11 Metodológicamente decidimos por protección de los desmovilizados individuales no utilizar ni su nombre real ni su alias habitual dentro de las estructuras a las que pertenecían. 
países. Alias "Juvenal" exmiembro de la compañía Francisco Bossio del ELN describe el "plan pistola" en Arauca y la utilización de la frontera para huir de las autoridades colombianas (Jader, 2017).

Es importante también indicar que, en las diferentes regiones del país, de acuerdo con los entrevistados, el "plan pistola" muestra períodos de intensificación, ligados esencialmente a la persecución por parte de las autoridades de ciertas conductas delictivas como el tráfico de estupefacientes, la minería ilegal, el contrabando, la siembra de cultivos ilícitos. No obstante, el patrón delictual en todo el territorio resulta ser el mismo.

De acuerdo con la Asociación Internacional de Análisis de la Delincuencia (IACA en adelante), existirá un patrón delictual cuando dos o más delitos reportados comparten una coincidencia en el comportamiento de los victimarios, las víctimas, las características del agresor, bienes afectados o lugar de ocurrencia. Lo anterior es corroborado en todas las veintiuna entrevistas practicadas. Por otro lado, la existencia de un patrón de macrocriminalidad exige que no exista relación conocida entre víctima y victimario, lo que también se presenta en el caso colombiano. En tercer lugar, los elementos comunes de las conductas hacen que los delitos sean claramente diferenciables de otras prácticas en los lugares en donde suceden. Otro elemento propio del patrón es que la duración de la actividad criminal debe tener una limitación temporal y un pináculo por ciclo (órdenes precisas para cumplir con la misión, verbigracia en la fase de una ofensiva táctica y una defensiva estratégica), lo que en el caso del plan sucede dependiendo del comportamiento operacional del Ejército en las zonas de influencia de los grupos armados. Lo anterior ocurre ahora con el Clan del Golfo y acaeció en su momento con el Cartel de Medellín a través de las órdenes de sicariar a los miembros del bloque de búsqueda (Booba, 2009).

\subsubsection{La estadistica del "plan pistola" contra miembros del Ejército Nacional}

La elaboración de la estadística de víctimas ocasionadas en el CANI colombiano en términos generales es uno de los principales problemas para la satisfacción integral de los derechos de millones de personas, entre ellos el de verdad. En términos económicos, sucedió lo mismo con la estructuración de la indemnización administrativa expresada en la Ley 1448 que ahora requerirá de nuevas reformas en términos generales.

La veeduría, por parte de las instancias legales designadas sobre lo que ha hecho la Unidad de Reparación de Victimas (UARIV en adelante) desde su creación es incontrovertible, se encuentra en deuda con las personas afectadas por la guerra. Es increíble que no resuelvan si quiera derechos de petición, siendo un derecho fundamental de todas las personas por mandato constitucional (UARIV, 2016). 
Una de las causales de los problemas estadísticos pasa por la ausencia de reconocimiento de ciertos sectores victimizados o la preponderancia mediática y política de otros. Así ocurrió durante años con los militares y policías victimizados, sin importar lo que expresarán la Ley 975, la Ley 1448 y la copiosa jurisprudencia interna (Marín y Mejía, 2015).

Ahora existe otro problema, el del reconocimiento limitado (capitis diminutio), por ejemplo, en términos de reparación económica de militares victimizados, amparado increíblemente solo por factores económicos con la Sentencia C-161 del 2016 de la Corte Constitucional, providencia que posiblemente no soportará el activismo judicial del número creciente de víctimas de las FFAA y que requerirá de una reforma urgente al régimen especial diseñado para un escenario totalmente diferente al de la reparación integral proveniente de una guerra. Afortunadamente, de acuerdo con nuestras últimas indagaciones, se está trabajando sobre una nueva política pública y los cambios constituyen en sí mismos un acto de reparación.

La figura 1 muestra a diciembre del 2017 el número de víctimas del Ejercito Nacional (Ejército Nacional, 1962) de acuerdo con los cruces de información realizados entre la UARIV y el MDN partiendo de la utilización de una base de datos interna que registra

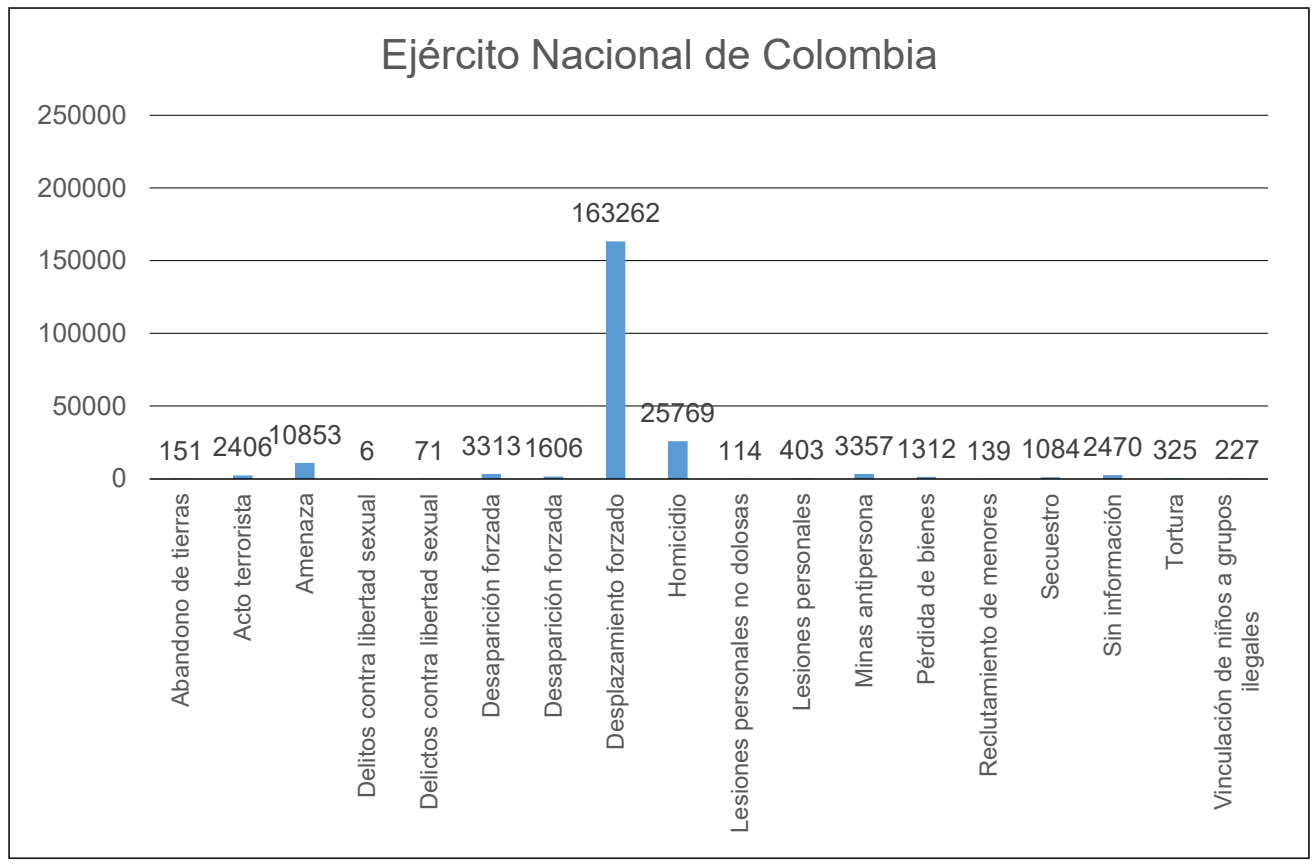

Figura 1. Víctimas pertenecientes al Ejército Nacional desde 2004 hasta diciembre de 2017 Fuente: elaboración propia con base en datos del MDN. 
hechos desde el 2004 (Sistema de Administración del Talento Humano. SIATH), así que el subregistro se apalanca como otra conclusión liminar. Las cifras desestiman las presentadas por el informe Basta ya, respecto al número de homicidios de combatientes (término asumido en un lenguaje propio de transición), lo que incluye a los ilegales (Centro Nacional de Memoria Histórica. CNHM, 2013).

La figura muestra un número de 25.679 homicidios cometidos contra miembros del Ejército Nacional en apenas 17 años de los 54 que lleva el CANI. También evidencia que existe una caracterización en 18 hechos victimizantes, lo cual demuestra la gravedad del fenómeno de victimización contra militares, no obstante que no existe ningún tipo de discriminación respecto a la forma de presentarse los homicidios (homicidios agravados, simples, en persona protegida, selectivos). Ahora bien, se registran en las siguientes tablas y gráficos las estadísticas sobre el "plan pistola" contra miembros del Ejército Nacional a partir de 2006, la información fue suministrada por el Comando de Personal de la Institución a través de la Dirección de Bienestar y Familia (Difab) y la Dirección de Preservación de la Fuerza (Dipse).

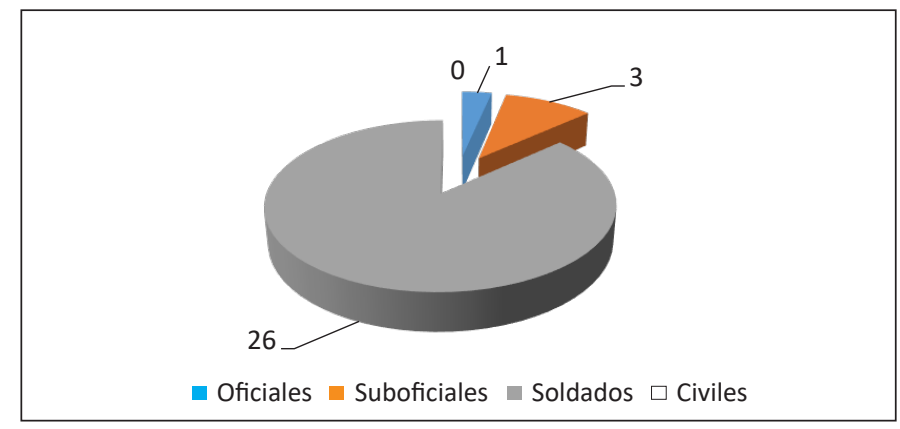

Figura 2. Discriminación de la afectación Fuente: EJC.

Tabla 1. Víctimas del "plan pistola" en EJC por grados

\begin{tabular}{lc}
\hline \multicolumn{2}{c}{$\begin{array}{c}\text { Víctimas "plan pistola" } \\
\text { 2006-2017 }\end{array}$} \\
\hline Oficiales & 1 \\
\hline Suboficiales & 3 \\
\hline Soldados & 26 \\
\hline Civiles & 0 \\
\hline Total & 30 \\
\hline
\end{tabular}

Fuente: EJC. 
La figura 2 y la tabla 1 muestran que desde el 2006 han sido asesinados 26 soldados, 3 suboficiales, 1 oficial del Ejército en circunstancias descritas en la definición propuesta en apartados previos. Es decir, en situaciones de vacaciones, permisos, licencias con lo cual además solo se describiría en parte la práctica macrocriminal del "plan pistola" dejando por fuera otras circunstancias esbozadas en los documentos y los testimonios de los desmovilizados. Este es un primer paso hacia la caracterización y el levantamiento de datos esenciales para comprender un fenómeno criminal desgarrador, ya que como lo muestra la tabla 2, ni siquiera las víctimas conocen la descripción fáctica de la terrible práctica y se denuncia como un homicidio cualquiera que va a engrosar estadísticas generales.

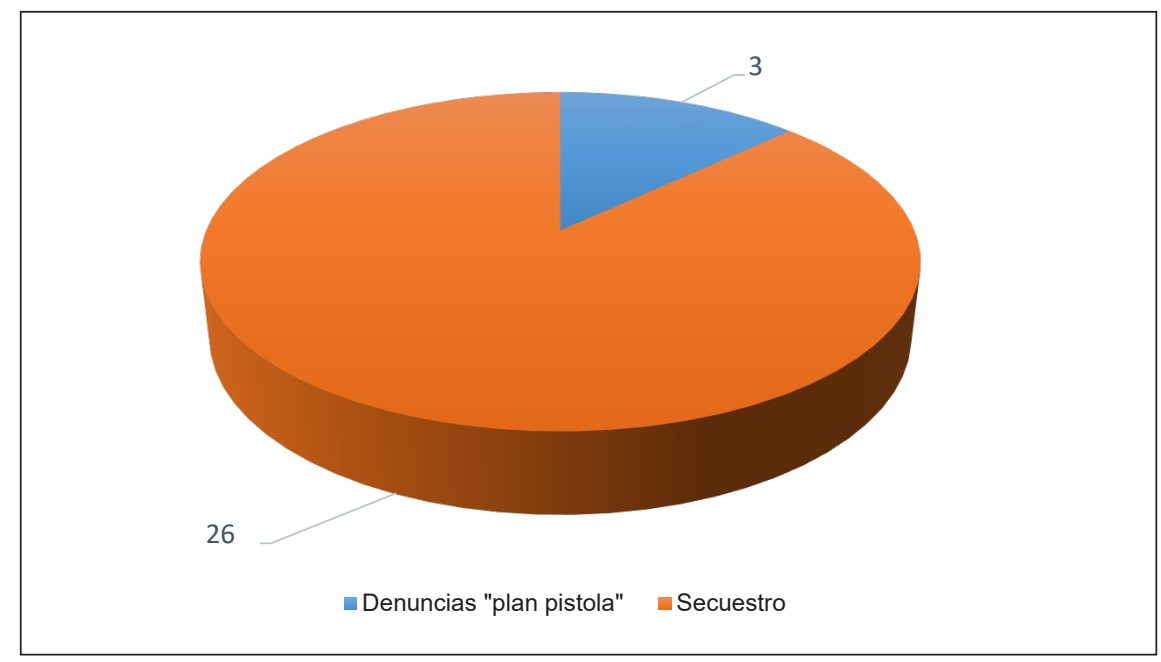

Figura 3. Porcentaje de denuncias

Fuente: EJC.

Tabla 2. Denuncias por plan pistola

\begin{tabular}{ll}
\hline \multicolumn{2}{c}{$\begin{array}{r}\text { Denuncias formuladas desde } 2001 \text { a septiem- } \\
\text { bre } 2017\end{array}$} \\
\hline Total denuncias & 96 \\
\hline Secuestro & 20 \\
\hline "Plan pistola" & 3 \\
\hline
\end{tabular}

Fuente: EJC.

Se espera como síntesis de este acápite, que las anteriores cifras motiven a las víctimas a exigir una descripción adecuada por parte de la UARIV sobre los hechos 
victimizantes provenientes de prácticas específicas del homicidio selectivo (asesinato o murder) como una forma de crimen de lesa humanidad en contra de miembros del Ejército Nacional. De igual manera que se refleje esta terrible realidad del CANI en el SIVJRN, especialmente en los escenarios de la JEP y de la Comisión de Esclarecimiento Histórico de la Verdad, la Convivencia y la No Repetición, para que no suceda lo que hace poco ocurrió en una Universidad de prestigio nacional e internacional con la intervención de una integrante del Sistema (ahora funcionaria estatal) quien manifestó que en Colombia no habían desaparecidos en las FFAA porque de acuerdo con el DIDH, el único que desaparecía personas era el Estado, este concepto está totalmente revaluado.

\section{CONCLUSIONES}

Más allá de las conclusiones preliminares advertidas a lo largo del artículo se pueden establecer algunas otras en esta fase de investigación relacionada con las graves violaciones a los DDHH de los miembros de las FFAA en el contexto de la guerra colombiana. Estas conclusiones serían las que a continuación se presentan.

El Estado colombiano tiene el deber de perseguir todos los crímenes internacionales ocurridos en su territorio sean ocasionados en el contexto del CANI o por fuera de él, esa es la única forma de cumplir con sus obligaciones internacionales.

Por otra parte, y no obstante que Colombia no tiene tipificados los crímenes de lesa humanidad, sí cuenta con una política criminal esbozada para la justicia transicional y ahora para la justicia ordinaria que le permitiría cumplir con sus deberes, flexibilizando en virtud del principio pro victimae el de legalidad penal y el subprincipio de tipicidad sin que tenga que hacer trasplantes inadecuados del derecho internacional. La guía interpretativa sí la brinda el ER.

Ahora bien, las Fuentes del derecho Internacional, especialmente las del DPI no niegan la posibilidad de que los militares (combatants) puedan ser víctimas de crímenes de lesa humanidad, en cualquier escenario, incluyendo el bélico y cuando se encuentren en circunstancias específicas de indefensión o vulnerabilidad no protegidas por el DIH a través del status de persona protegida.

Si bien el punto no es pacífico en la jurisprudencia internacional estudiada, especialmente en la ulterior jurisprudencia del TPIY, el TPIR y las salas especiales de Camboya y en la CPI sobre los casos de hors de comba", resulta fuerte el argumento de que el concepto de población civil es amplio e incluyente e integra a combatientes, lo cual fue discutido desde los estatutos del Tribunal de Núremberg, el Lejano Oriente y la Ley 10 del Consejo de Control Alemán (CCA, 1945) al tratar de que no se gene- 
rara impunidad frente a los hechos ocasionados por los Nazis en contra de la propia población alemana.

Es bueno precisar que, metodológicamente el trabajo de sensibilización, descripción y análisis sobre nuevos hechos victimizantes requiere de un esfuerzo especial sobre fuentes primarias, lo cual no se puede hacer sin la colaboración y la información otorgada por las entidades y organismos estatales. El subregistro resulta impresionante.

Es pertinente indicar como conclusión que existe afortunadamente, al terminar el año 2018, un reconocimiento en la mayoría de instancias nacionales acerca de la existencia de víctimas militares y policiales ocasionadas en la guerra colombiana de los últimos 54 años, pero investigarlas bajo la tipificación exclusiva de crímenes de guerra, dejaría miles de casos en total impunidad.

El "plan pistola" contra los miembros de las FFAA fue y sigue siendo una práctica criminal sistemática y generalizada que nació con los grupos al margen de la ley en Colombia, bien de extrema izquierda o de extrema derecha, y debe ser mostrada y descrita en su real dimensión como una garantía de no repetición. Ante el SIVIRNR los exmiembros de las FARC-EP, hoy partido político deben satisfacer los derechos de las víctimas y mostrar hasta los más mínimos detalles de los procesos de victimización. Fue claro en el testimonio de los desmovilizados que ellos conocían claramente en qué consistía el plan y cuáles eran las políticas de una organización como las FARC o el ELN.

Habrá que decir también que la presente investigación abre las puertas para próximas indagaciones sobre con otros hechos victimizantes en relación con sectores de la población afectados por el CANI y los diferentes actores armados.

Finalmente, han sido evidenciadas líneas argumentativas jurídicas, jurídico-políticas para establecer la presencia de crímenes de lesa humanidad contra la población civil uniformada en Colombia. Las cifras obtenidas, los testimonios brindados en el estudio de campo pueden generar en un contexto de justicia transicional luego de la entrada en vigencia de la Corte Penal Internacional (Fuentes, 2011, pp,119-140), elementos nunca estudiados en el contexto latinoamericano.

\section{REFERENCIAS}

Ambos, K., Malarino, E. y Elsner, G. (Eds.). (2009). Justicia de transición. Montevideo: Konrad Adenuer Estiftung.

Barbosa, G. y Bernal, C. (2015). El análisis de contexto en la investigación penal: crítica del trasplante del derecho internacional al derecho interno. Bogotá: Universidad Externado de Colombia. 
Bassiouni, C. (1992). Crimes Against Humanity in International Criminal Law. Londres: Martinus Nijhoff.

Booba, R. (2009). Crime analysis with crime maping. Thousand Oaks: Sage.

Bouthol, G. (1970). Ganar la paz, evitar la guerra. Barcelona: Plaza y Janés.

Cassese, A. E Delmas, M. (Eds.). (2004). Crímenes y jurisdicciones internacionales. Bogotá: Grupo editorial Norma.

Cassese, A. (2008). Crimes against humanity. Comments on some problematical aspects. En A. Cassese (Ed.), The Human Dimension of international law. (pp. 429-447). Oxford: Oxford University Press.

Centro Nacional de Memoria Histórica. CNMH. (2013). Basta ya. Bogotá: Centro Nacional de Memoria Histórica.

Clausewitz, C. (2005). De la guerra. Madrid: La esfera de los libros.

Comité Internacional de la Cruz Roja. CICR. (1977a). Protocolo I adicional a los Convenios de Ginebra de 1949, relativo a la protección de las víctimas de los conflictos armados internacionales. Ginebra: CICR.

Comité Internacional de la Cruz Roja (CICR). (1977b). Protocolo II adicional a los Convenios de Ginebra de 1949, relativo a la protección de las víctimas de los conflictos armados no internacionales. Ginebra: CICR.

Consejo de Control Alemán. CCA. (1945). Control Council Law 10. Punishment of Persons guilty of War Crimes, Crimes Against Peace and Crimes Against Humanity. Recuperado de http://hrlibrary. umn.edu/instree/ccnol0.htm

Congreso de la República. (2005). Ley 975 de julio 25 por la cual se dictan disposiciones para la reincorporación de miembros de grupos armados organizados al margen de la ley, que contribuyan de manera efectiva a la consecución de la paz nacional y se dictan otras disposiciones para acuerdos humanitarios. Diario Oficial 45.980 de julio 25 de 2005.

Congreso de la República. (2011). Ley 1448 de junio 10 por la cual se dictan medidas de atención, asistencia y reparación integral a las víctimas del conflicto armado interno y se dictan otras disposiciones. Diario oficial 48.096 de junio 10 de 2011.

Corte Constitucional de Colombia. (1997). Sentencia C-456 de septiembre 23. M.P. Arango Mejía, J. y Cifuentes Muñoz, E.

Corte Constitucional de Colombia. (2002a). Sentencia C-578 de julio 30. M. P. Cepeda Espinosa, M. Corte Constitucional de Colombia. (2002b). Sentencia C-1076 de diciembre 5. M. P. Vargas Hernández, C. Corte Constitucional de Colombia. (2006a). Sentencia C-370 de mayo 18. M. P. Cepeda Espinosa, M. y otros.

Corte Constitucional de Colombia. (2012). Sentencia C-290 de abril 18. M. P. Sierra Porto, H.

Corte Constitucional de Colombia. (2016). Sentencia C-161 de abril 7. M. P. Vargas Silva, L.

Corte Constitucional de Colombia. (2017a). Comunicado 55 de noviembre 14. M. P. Guerrero Pérez, L. Corte Constitucional de Colombia. (2017b). Sentencia C-674 de noviembre 14. M. P. Guerrero Pérez, L. Corte EDH. (2001a). Papon vs. France. Recuperado de http://www.internationalcrimesdatabase.org/ Case/789 
Corte EDH. (2001b), Streletz, Kessler \& Krens vs. Germany. Recuperado de hudoc.echr.coe.int/ webservices/content/pdf/001-59353?TID...

Corte EDH. (2008). Korbely vs. Hungría. Recuperado de http://hudoc.echr.coe.int/eng?i=001-88429

Corte IDH. (2006). Almonacid Arellano vs. Chile. Recuperado de http://www.corteidh.or.cr/docs/casos/ articulos/seriec_154_esp.pdf

Corte IDH. (2010). Gomes Lund y otros (Guerrilha Do Aragua) vs. Brasil. Recuperado de http://www. corteidh.or.cr/docs/casos/articulos/seriec_219_esp.pdf

Corte Penal Internacional. CPI. (2011). Informe preliminar sobre Colombia. Recuperado de https:// www.icc-cpi.int/NR/rdonlyres/63682F4E-49C8-445D-8C13-F310A4F3AEC2/284116/OTPReportonPreliminaryExaminations13December2011.pdf

Corte Penal Internacional. CPI. (2014). Prosecutor v. Germain Katanga. Recuperado de https://www. icc-cpi.int/iccdocs/pids/publications/KatangaEng.pdf

Corte Penal Internacional. CPI. (2016). Informe sobre las actividades del examen preliminar. Situación en Colombia. La Haya: CPI-Fiscalía.

Corte Penal Internacional. CPI. (2017). Escrito de amicus curiae de la Fiscal de la Corte Penal Internacional sobre la Jurisdicción Especial para la Paz. La Haya: Oficina de la Fiscalía de la CPI.

Corte Suprema de Justicia. Sala de Casación Penal. (2009). Sentencia 32022 de septiembre 21. M. P. Espinosa Perea, S.

"Crazy". (2017). Entrevista a desmovilizado sobre plan Pistola en Cauca. Entrevista con J. C. Mejía Azuero.

Decu, A. (2013). The Aftermath of dissident Re-education: A comparative Approach of Romania's Pitesti Phenomenon and the Chinese Labour Camps. Revista Bibliotecii Nationale, 46-49.

Dember, A. (2017). Plan Pistola en Tumaco. Entrevista con J. C. Mejía Azuero.

Deutsch, M. y Coleman, P. (2000). The Handbook of Conflict Resolution. Theory and practice. San Francisco: Jossey Bass Publishers.

Dungel, J. (2009). Defining victims of crimes against humanity: Martíc and the international Criminal Court. Leiden Journal of International Law, 22, 727-752.

Ejército Nacional. (abril de 1962). Plan de operaciones Lazo. Bogotá: Ejercito Nacional.

Estado Mayor del Bloque Oriental. EMBO. (2000). Órdenes desde el Yari. Yari: FARC.

Estado Mayor del Bloque Oriental. EMBO. (2002). Orientaciones generales. Macarena: FARC.

FARC. (2007). Compendio Militar. Bogotá: FARC.

Futamura, M. (2006). Individual and collective Guilt: Post - War Japan and The Tokio War Crimes Tribunal. European Review 4.

Fuentes, X. (2011). Principio de Complementariedad en la práctica de la Corte Penal Internacional. Revista de Estudios Internacionales. Universidad de Chile, 119-140.

Fisas, V. (2010). iAlto al fuego! Manual de procesos de paz. Barcelona: Icaria editorial / Escola de Cultura de Pau. 
Fiscalía General de la Nación. (2016 a). Directiva 001 de marzo 27 por medio de la cual se adoptan los fundamentos jurídicos para el análisis de la responsabilidad del dirigente por el hecho de los combatientes en los casos de la imputación de violaciones masivas a los derechos humanos en Colombia. Bogotá: Fiscalía General de la Nación.

Fiscalía General de la Nación. (2016 b). Directiva 002 de marzo 27 por medio de la cual se adoptan los fundamentos jurídicos para la aplicación del crimen de lesa humanidad dentro de la Fiscalía General de la Nación. Bogotá: Fiscalía General de la Nación.

Fiscalía General de la Nación. (2016 c). Directiva 003 de marzo 27 por medio de la cual se adoptan criterios sobre la imprescriptibilidad de los delitos de lesa humanidad. Bogotá: Fiscalía General de la Nación.

Forero, J. (. (2017). Justicia transicional en Colombia: un nuevo camino hacia la paz. Valencia: Tirant lo Blanch, Universidad del Rosario.

Galtung. J. (1998). Tras la violencia, 3R: reconstrucción, reconciliación, resolución. Afrontando los efectos visibles e invisibles de la guerra y la violencia. Bilbao: Bakeaz.

Galtung, J. (2006). La transformazione dei conflitti con mezzi pacifi. Torino: Centro de Studi Sereno Regis.

García, D. (2015). La experiencia americana en la aplicación de la justicia transicional. En Corte Suprema de Justicia (Ed.), Justicia transicional, paz y posconflicto (pp. 79-86). Bogotá: Imprenta Nacional.

Greenwood, C. (1991). Customary law status of the 1977 Additionnal Protocols. En Delissen, A. y Tanja, G. (Eds.), Essays in honour of Frits Kalshoven, pp. 93-144. Dordrecht: Martinus Nijhoff.

Guzmán, M., Fals, O. y Umaña, E. (2015 a). La violencia en Colombia (tomo I ). Bogotá: Taurus.

Guzmán., Fals., y Umaña. (2015 b). La violencia en Colombia (tomo II). Bogotá: Taurus.

Hoffman, F. (2007). Conflict in the 21st Century. The Rise of the Hybrid Wars. Arlington: Potomac Institute for Policy Studies.

Huertas, Ó y Cáceres, V. (2017). JEP: Jurisdicción Especial para la Paz. Bogotá: Ibáñez.

"Jader". (2017). Entrevista sobre el plan pistola en Arauca. Entrevista con J. C. Azuero.

Joinet, L. (1985). Study on Amnesty Laws and Their Role in the Safeguard and Promotion of Human Rights. Preliminary Report by Mr. Louis Joinet. Ginebra: ONU.

Joyner, C. y Bassiouni, M. (Eds.). (1998). Reigning in Impunity for International Crimes and Serious Violations of Fundamental Human Rights. Siracusa: Association Internationale de Droit Pén.

Kaldor, M. (2001). New and Old Wars: Organized Violence in a Global Era. Stanford: Stanford University Press.

Killean, M., Dowds, E. y Kremer, A. (2017). Soldiers as victims al ECCC: Exploring the concept of civilian in crimes against humanity. Leiden Journal of International Law, 1-33.

Lind, W., Nightengale, K, Schmitt, J., Sutton, J. y Wilson, G. (1989). The Changing face or war. Into the fourth generation. Marine Corps Gazette, 4, 22-26.

Marín, A. y Mejía, J. (2015). Miembros de las Fuerzas Armadas como víctimas. Enfoques desde la justicia transicional en Colombia. Bogotá: Ibáñez.

Ministerio de Defensa Nacional. MDN. (2017). Informe estadístico de miembros de las FFAA como víctimas en Colombia. Bogotá: MDN. 
Mejía, J. y Chaib, K. (2012). Derecho Internacional Humanitario. Bogotá: Panamericana -Universidad Los libertadores.

Mejía, J. y Sandoval, J. (2013). Derecho Penal Internacional y Derecho Internacional Penal. Medellín: Universidad de Medellín.

Mejía, J. (2016). posconflicto en Colombia. Transición militar y policial. Recuperado de: https://www. opendemocracy.net/democraciaabierta/jean-carlo-mej-azuero/post-conflicto-en-colombia6-transici-n-militar-y-policial-c

Mejía, J. (2009). Las autodenominadas FARC y sus ataques contra la democracia en el primer semestre del 2006. En J. Mejía (Ed.), Conflicto y paz en Colombia (pp. 101-128). Bogotá: Temis.

Meron, T. (1989). Human Rights and humanitarian norms as customary law. Oxford: Clarendon.

Moir, L. (2006). Crimes against humanity in historical perspective. En L. Moir (Ed.), New Zeland Yearbook of International Law (pp.101-108). Wellington: University of Canterbury.

Nguyen, V. (1968). People's War, People's Army. Nueva York: Bantam Books.

Nicholson, J. (2016). Is the Requirement that Crimes Against Humanity be Committed Against a "Civil Population" Really Necesessary? Recuperado de http://opiniojuris.org/?s=Nicholson

Pictet, J. (1982). Desarrollo y principios del Derecho Internacional Humanitario. Recuperado de https:// www.icrc.org/es/doc/resources/documents/misc/desarrollo_y_principios.htm

Pizarro, E. (1991). Las FARC: de la autodefensa a la combinación de todas las formas de lucha. 1949-1966. Bogotá: IEPRI-Tercer Mundo Editores.

Sierra-Zamora, P. A., Cárdenas, J. A. C., Ortiz, D. A. C., E Caballero, N. P. (2019). Terrorism by the FARC-EP and public policies oriented towards national security in Colombia during 1990-2000. Revista Científica General José María Córdova, 17(26), pp. 309-325.

Sierra Zamora, P, Carvajal Martínez, J. E., Pérez Salazar, B., Gómez Jaramillo, A., Beltrán Hernández, D., Romero Romero, C., \& Romero Sánchez, A. (2015). El entramado penal, las políticas públicas y la seguridad.

Sierra-Zamora, P. A. (2018). La tutela de los Derechos Humanos en situaciones de postguerra: el caso colombiano. Working Paper, 2.

"Sangrón". (2017). Entrevista a desmovilizado sobre el Plan Pistola. Entrevista con J. C. Mejía Azuero.

Schabas, W. (2012). Unimaginable atrocities, justice, politics and rights at the war crimes Tribunals. Oxford: Oxford University Press.

Teitel, R. (2000). Transitional Justice. Nueva York: Oxford University Press.

Tribunal Militar Internacional. IMT. (1945). Charter of the International Military Tribunal, annex to Agreement for the Prosecution and Punishment or the major war criminals of the European Axis, Art. 6 ( C ). Núremberg: Allied Nations.

Tribunal para el Genocidio Camboyano. ECCC. (2010). The Prosecutor vs. Kaing Guek Eav. Recuperado de http://www.internationalcrimesdatabase.org/Case/792

Tribunal para el Genocidio Camboyano. ECCC. (2014). The Prosecutor vs. Nuon Chea y Khieu Samphan. Recuperado de https://www.eccc.gov.kh/en/indicted-person/nuon-chea 
Tribunal Penal Internacional para la Antigua Yugoslavia. TPIY. (1995). Prosecutor v. Tadic. Decision of the defense Motion for Intelocutoty Appeal on Jurisdiction. Recuperado de https://casebook. icrc.org/case-study/icty-prosecutor-v-tadic

Tribunal Penal Internacional para la Antigua Yugoslavia. TPIY. (1998). Prosecutor vs. Delalic y otros. Recuperado de http://www.icty.org/x/cases/mucic/tjug/en/

Tribunal Penal Internacional para la Antigua Yugoslavia. TPIY. (1999). The Prosecutor vs. Jelisic. Recuperado de http://www.icty.org/x/cases/jelisic/tjug/en/jel-tj991214e.pdf

Tribunal Penal Internacional para la Antigua Yugoslavia. TPIY (2000a).Kupreskic y otros. Recuperado de http://www.icty.org/en/press/judgement-kupreskic-and-others-case-five-accused-sentencedterms-imprisonment-ranging-6-25

Tribunal Penal Internacional para la Antigua Yugoslavia. TPIY (2000b). The Prosecutor vs. Blaskic. Recuperado de http://www.icty.org/x/cases/blaskic/tjug/en/bla-tj000303e.pdf

Tribunal Penal Internacional para la Antigua Yugoslavia. TPIY (2001). The Prosecutor vs. Kordic y Cerquez. Recuperado de http://www.icty.org/x/cases/kordic_cerkez/acjug/en/cer-aj041217e.pdf

Tribunal Penal Internacional para la Antigua Yugoslavia. TPIY (2007). The Prosecutor v Mrksic y otros. Recuperado de http://www.icty.org/x/cases/mrksic/acjug/en/090505.pdf

Tribunal Penal Internacional para la Antigua Yugoslavia. TPIY (2008). Prosecutor vs. Martic. Recuperado de https://www.refworld.org/cases,ICTY,469de5652.html

Tribunal Penal Internacional para Ruanda. TPIR. (1998). The Prosecutor vs. Akayesu. Recuperado de https://casebook.icrc.org/case-study/ictr-prosecutor-v-jean-paul-akayesu

Tribunal Penal Internacional para Ruanda. TPIR. (1999).The Prosecutor vs. Kayishema. Recuperado de http://www.internationalcrimesdatabase.org/Case/134

Tribunal Penal Internacional para Ruanda. TPIR. (2008). The prosecutor vs. Théoneste Bagosora y otros. Recuperado de http://unictr.irmct.org/en/news/military-trial-prosecutor-vs-theonestebagosora-anatole-nsengiyumva-aloys-ntabakuze-and-gratien

Tribunal Penal Internacional para Ruanda. TPIR. (2014). The Prosecutor v Ndindiliyimana, Nzuwonemeye, Sagahutu. Recuperado de http://www.internationalcrimesdatabase.org/Case/809/ Ndindiliyimana-et-al/

Ugarriza y Pabón. (2017). Militares y guerrillas. Bogotá: Universidad del Rosario.

Unidad de Reparación de Víctimas. UARIV. (2016). Registro único de víctimas. Recuperado de http:// rni.unidadvictimas.gov.co/RUV

Vieira, G. (1964). La Combinación de todas las formas de lucha. Bogotá: Sudamérica.

"Zucarina". (2017). Plan pistola en Toledo, Norte de Santander. Entrevista con J. C. Azuero. 